\title{
Enhancing Vibration Reduction on Lightweight Lower Control Arm
}

\author{
Alessandro Messana $\left(\mathbb{D},{ }^{1}\right.$ Alessandro Ferraris $\left(\mathbb{D},{ }^{2}\right.$ Andrea G. Airale ${ }^{(D)},{ }^{2}$ \\ Alessandro Fasana $\mathbb{D}^{\mathbb{D}},{ }^{1}$ and Massimiliana Carello $\mathbb{D}^{1}$ \\ ${ }^{1}$ DIMEAS, Politecnico di Torino, Torino 10129, Italy \\ ${ }^{2}$ BeonD Srl, Torino 10129, Italy \\ Correspondence should be addressed to Alessandro Messana; alessandro.messana@polito.it
}

Received 18 June 2020; Revised 8 September 2020; Accepted 29 September 2020; Published 23 October 2020

Academic Editor: Yuanping Xu

Copyright ( $\odot 2020$ Alessandro Messana et al. This is an open access article distributed under the Creative Commons Attribution License, which permits unrestricted use, distribution, and reproduction in any medium, provided the original work is properly cited.

\begin{abstract}
This paper describes the design procedure to enhance the damping properties of a multimaterial lightweight suspension arm for a $\mathrm{C}$-segment vehicle. An innovative viscoelastic material has been used to join carbon fiber with steel that has a function of passive constrained layer damper and adhesive simultaneously. Therefore, the hybrid technology applied has been focused on reducing the LCA mass, diminishing the steel thickness, and adding a CFRP tailored cover without compromising the global mechanical performance. Particular attention has been paid to the investigation of the dynamic response in terms of vibration reduction, especially in the range of structure-borne frequencies of $0-600 \mathrm{~Hz}$. Two different viscoelastic materials have been evaluated in such a way to compare their stiffness, damping, and dynamic properties. The experimental test results have been virtually correlated with a commercial FEM code to create the respective material card and predict the real behavior of the LCAs (original and hybrid). The experimental modal analysis has been performed and compared on both the arms highlighting a very good correlation between virtual and experimental results. In particular, the hybrid LCA allows an interesting improvement of damping ratio, about 3,5 times higher for each eigenmode than in the original solution.
\end{abstract}

\section{Introduction}

The hybridization and electrification of vehicle powertrains are pushing carmakers to reduce the mass of vehicles to extend as much as possible the vehicle covered distance. Moreover, the EU has recently issued regulations ordering a cut of $30 \%$ of the average emissions of new cars in 2030, over the fixed values of $95 \mathrm{~g} \mathrm{CO}^{2} / \mathrm{km}$ for passenger cars of 2021 [1]. Since the suspension systems build up $25 \%$ of the whole mass of a vehicle [2], their optimization would cause advantages not only in consumption reduction but also in handling and vibroacoustic comfort.

Thus, the application of advanced materials, like Carbon Fiber Reinforced Plastic (CFRP), to reduce suspension mass is becoming a common practice [3-6]. Lightweight materials can significantly change the NVH (Noise Vibration and Harshness) behavior of a component [7]. Noise and vibration are an increasingly important issue in the automobile industry, for implications on both environmental noise pollution and comfort perceived by drivers and passengers. In addition, the vehicle suspension system has a crucial role in vibration transmission and its excitations are located in the structure-borne transmission path, between the road-tire interaction and the vehicle body [8]. In particular, the lower control arm (LCA) is one of the main transfer paths for vibrations coming from the wheels into the chassis. The reduction of these vibrations is considered by carmakers a design objective because they can influence the comfort of passengers, for example when driving through a train crossbeam or running over small obstacles.

Only a small part of the road vibrations is damped by the two elastomeric bushings of the swing arm [9]. In fact, although soft bushings improve comfort and increase vibration insulation, they drastically degrade vehicle drivability 
and handling. However, the high axial and radial stiffness of the bushings transfer the vibration directly to the subframe. In this context, Salloum et al. $[10,11]$ present the design of a lightweight lower control arm with a new methodology for a full design of a smart structure by using piezoceramics semiactive damping. However, experimental modal analysis shows a peak reduction of $6 \mathrm{~dB}$ at the $1^{\text {st }}$ resonance frequency instead of the predicted results.

This paper is focused exclusively on enhancing the damping properties of a multimaterial lightweight suspension arm made of steel and carbon fiber. For this reason, any kind of vibration reduction effects has been investigated to the global suspension system. The novelty of this research is represented by the application of an innovative low-density viscoelastic interface that works simultaneously as damper and adhesive. Moreover, the complete research activity has been conducted on an off-the-shelf component actually installed on a real vehicle. This is a plus that will allow integrating the multimaterial LCA on a realistic car permitting a "ready-to-run" approach. Therefore, starting from an existing component (made of steel), the LCA mass has been reduced by using a hybrid technology, diminishing the steel thickness and adding a carbon fiber tailored cover. Moreover, particular attention has been paid to the investigation of the dynamic response in terms of vibration reduction in the range of structureborne frequencies of $0-600 \mathrm{~Hz}$. Intensive testing activities have been conducted to investigate, firstly, damping properties on this innovative viscoelastic material by comparing two different compounds, secondly, the modal response of the original arm (also called baseline) and the multimaterial one (also called hybrid). The experimental characterization has been completed by a virtual correlation analysis in order to carry out the material card using Altair Optistruct solver for FEM simulation. Finally, a comparison has been conducting on both baseline and hybrid component to validate the entire design process and evaluate the real damping performance.

1.1. The Multimaterial LCA Concept Description. A C-segment vehicle front lower control arm has been chosen as the case study for this paper. The LCA is manufactured with a single metal sheet made of microalloyed HSLA steel (Figure 1). The original mass of the complete assembly is about $3,45 \mathrm{~kg}$ which becomes $2,16 \mathrm{~kg}$ without the lower ball joint and bushing.

One of the major challenges in multimaterial design consists in joining dissimilar materials. Traditional techniques such as clinching or riveting are not suitable for the lower control arm applications. Neither standard liquid adhesive is a viable solution for the following reasons:

(i) Complex geometry shape that makes glue distribution difficult

(ii) Difficulty in controlling glue thickness variation, especially inside the embosses

(iii) Difficulty in finding adhesive types that are compliant to prepregs autoclave curing cycles

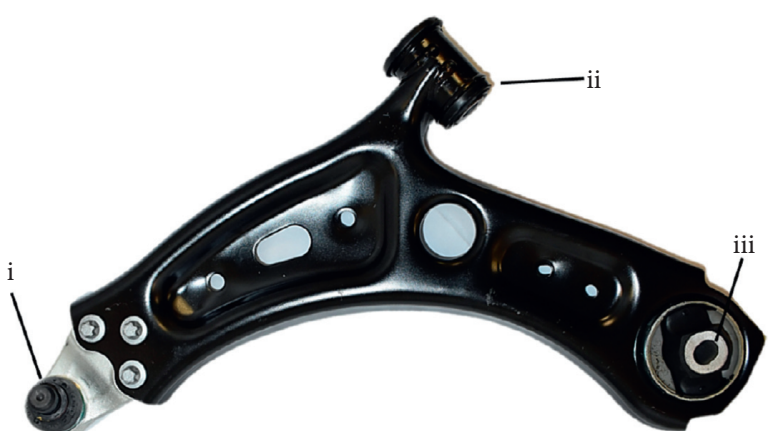

FIGURE 1: Lower control arm: the complete assembly is composed of the lower ball joint (i), front bushing (ii), and rear bushing (iii).

On the other hand, the direct contact between CFRP and steel represents the best solution from the mechanical performance point of view. Nevertheless, the NVH properties of the laminate could not improve considerably due to the very low damping properties of these two materials. For these reasons, an innovative technology to couple carbon fiber and steel has been used to face the problem of joining dissimilar materials and match the design target. These particular Viscoelastic Materials (called Kraibon) are manufactured by KRAIBURG GmbH and consist in a calibrated rubber foil that works as passive constrained layer damper (PCLD) and adhesive simultaneously. The Kraibon is a thin calibrate film made of non-cross-linked rubber that hardens within the component laminate in the same curing process. The important advantages are the direct integration of the elastomers in the normal manufacturing process and the direct connection without additional bonding agents. Moreover, the viscoelastic properties are tuned to improve $\mathrm{NVH}$, impact, and splintering behavior. In fact, several scientific papers [12-14] confirmed the excellent vibroacoustic properties of these VEMs especially applied on automotive components such as a CFRP car door and hybrid laminate [15]. In addition, the integration of Kraibon enhances the damage tolerance capabilities of the laminate. These results have also been validated in $[16,17]$, where Kraibon materials have been used to improve energy absorption and reduce delamination. The Kraibon material works also as an insulating layer between the two materials, which prevents corrosion and considerably extends the service life of the component (characteristic confirmed by [18]). From the manufacturing point of view, the main advantages are represented by the high draping capability and the perfect compatibility with prepregs curing cycles. Moreover, the substrates do not need surface pretreatments before film application.

Hence, a hybrid design solution has been developed to satisfy the requirements of lightweight and vibration damping. The proposed solution for the hybrid lower control arm consists in coupling a carbon fiber cover on the reduced thickness metal shape of the original arm, by using the Kraibon material as an interface between steel and CFRP (see Figure 2). This process allows evaluating the potential and the capabilities of the hybridization without redesigning 


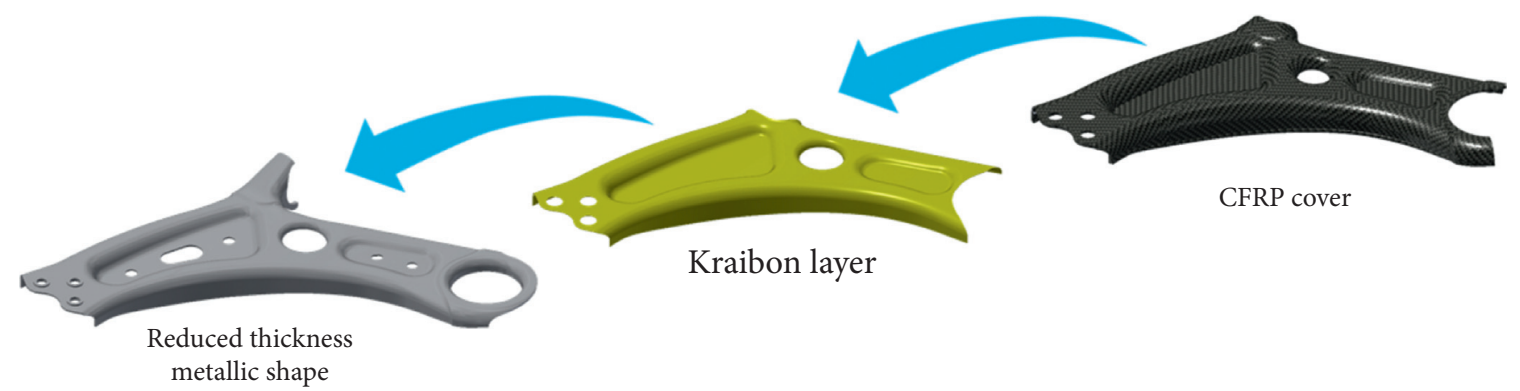

FIGURE 2: Hybrid LCA concept: the Kraibon foil is the interface layer between the machined metallic shape and the structural cover in CFRP.

the component totally. Hence, the original shape is kept almost unmodified, with the exception of the areas reinforced by carbon fibers through high-performance fabrics and unidirectional disposition.

Laminate thickness, fiber orientation, and ply stacking sequence have been defined through a CAE structural optimization by using Altair Optistruct. As regards manufacturing technology, a standard hand layup process has been considered feasible for one prototype building. Therefore, the design requires different analysis levels that follow precise workflow, for example, the building block approach [19], in order to carry out the best performance solution. Focusing on the material for structural tailored cover, two different kinds of fiber reinforcements have been selected: a unidirectional solution and two different fabrics. Their main characteristics have been reported in Table 1.

In addition, composite material design needs cuttingedge computational tools and methodology to model and predict the performance of the component and obtain reliable simulation. The elaboration of the experimental data is also necessary to define a specific methodology to define the virtual material card in order to obtain a robust and reliable virtual model for the final correlation on the Optistruct solver.

According to the research aim, the main tasks have been focused to improve the global damping effect compared to the conventional component to reduce vibration transmission to the chassis and, simultaneously, to obtain the minimum mass and the same mechanical stiffness.

\section{Viscoelastic Material Characterization}

2.1. Experimental Damping Properties Evaluation. For the purpose of this research activity, Kraibon ${ }^{\circledR}$ supplied two different compounds named HAA 9275/45 and HVV 9632/ 59. Elastomeric materials as Kraibon ${ }^{\circledR}$ are generally included inside the viscoelastic category. In particular, HAA 9275/45 is an Ethylene Propylene Diene monomer (EPDM) while HVV 9632/59 is an Ethylene Acrylate Monomer (AEM). The tests have been performed according to the ASTM E756-05 standard (also known as Oberst test) [20] to obtain the dynamic and damping properties. In addition, both VEMs have been subjected to a test at different temperatures (between $-20^{\circ} \mathrm{C}$ and $60^{\circ} \mathrm{C}$ ) according to the SAE J 1637 [21] and to an aging cycle of $750 \mathrm{~h}$, according to the IEC 60068 [22].
TABLE 1: Carbon fiber materials adopted on the structural cover of the hybrid LCA.

\begin{tabular}{lccc}
\hline Material & Weave & Task & Matrix \\
\hline M46J150 g/m $/ \mathrm{m}^{2}$ & Unidirectional & $\begin{array}{c}\text { Structural } \\
\text { reinforcement }\end{array}$ & Epoxy \\
T700 $430 \mathrm{~g} / \mathrm{m}^{2}$ & Twill $2 \times 2$ & Structural & Epoxy \\
T300 $240 \mathrm{~g} / \mathrm{m}^{2}$ & Twill $2 \times 2$ & Aesthetic & Epoxy \\
\hline
\end{tabular}

This section presents the results obtained from the Oberst test on the two elastomeric materials called, for simplicity, HAA and HVV. The fitting procedure to find out the natural frequencies and the damping ratios for each mode has been carried out by using a properly MATLAB script. Four specimens (for each material) without treatment have been tested twice before and after $750 \mathrm{~h}$ aging, while another four have been tested only in compliance with the SAE J1637. This procedure has been replicated for each viscoelastic material. Oberst tests have also been done on the structural beam made of T300 carbon fiber, but no tests on aged structural beam have been performed because it has already been demonstrated that T300 epoxy carbon fibers performances are almost constant in temperature after treatment [14].

Figure 3 reports the one-side beams tested for HVV and HAA.

As shown in Figure 4, both materials have a quite constant trend along frequency. In particular, HVV has the best performance in terms of loss factor $\zeta$ before and after the climatic chamber treatment. The aging has increased the loss factor value at the second natural frequency while it decreased in the last frequency. Aging in HAA materials has globally increased the loss factor curve maintaining also its peak at the $3^{\text {rd }}$ frequency.

As regards $\mathrm{E}$ modulus, the situation is reversed as reported in Figure 5. HAA material has always the highest values of $\mathrm{E}$ modulus before and after $750 \mathrm{~h}$ even though the aging causes a sensible drop of performance in all the frequency range. On the contrary, HVV is not affected by the aging maintaining the same constant trend with respect to the frequency.

Figure 6 summarizes the properties variations with temperature. It can be observed that $\mathrm{HVV}$ loss factor $\zeta$ is always higher than HAA in the tested range of frequency. The maximum peak is reached at $-10^{\circ} \mathrm{C}$ by the $\mathrm{HVV}$ that maintains a very good value until $30^{\circ} \mathrm{C}$. After that, the loss factor $\zeta$ tends to remain quite constant. On the other hand, HAA increases its 
HVV-no aging

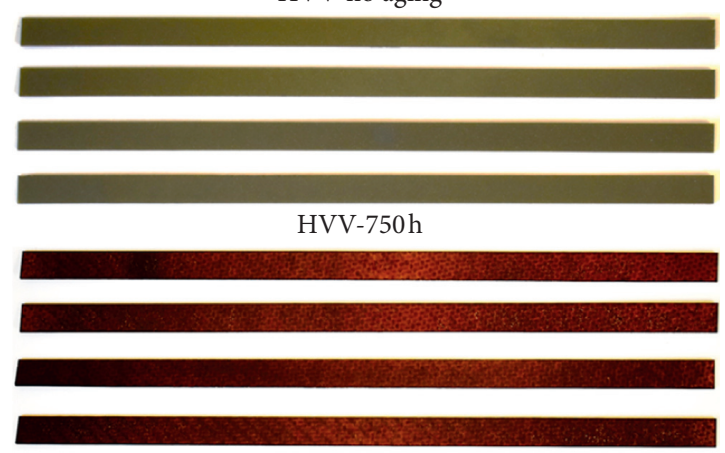

(a)
HAA-no aging

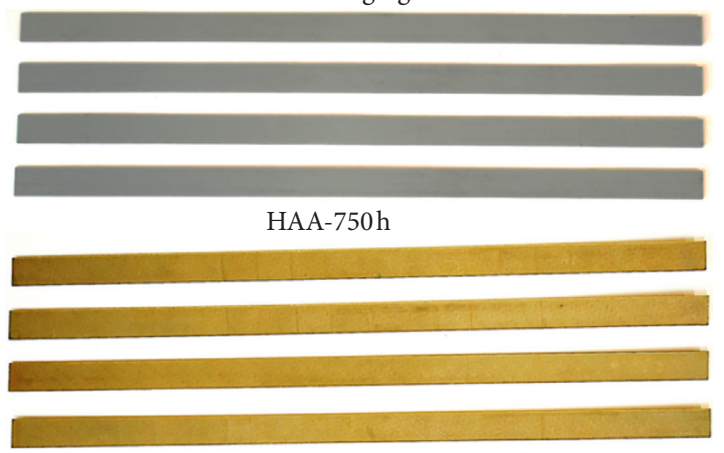

(b)

Figure 3: (a) HVV. (b) HAA. Specimen before and after the aging treatment of $750 \mathrm{~h}$. The significant color variation due to the aging effect can be noticed.

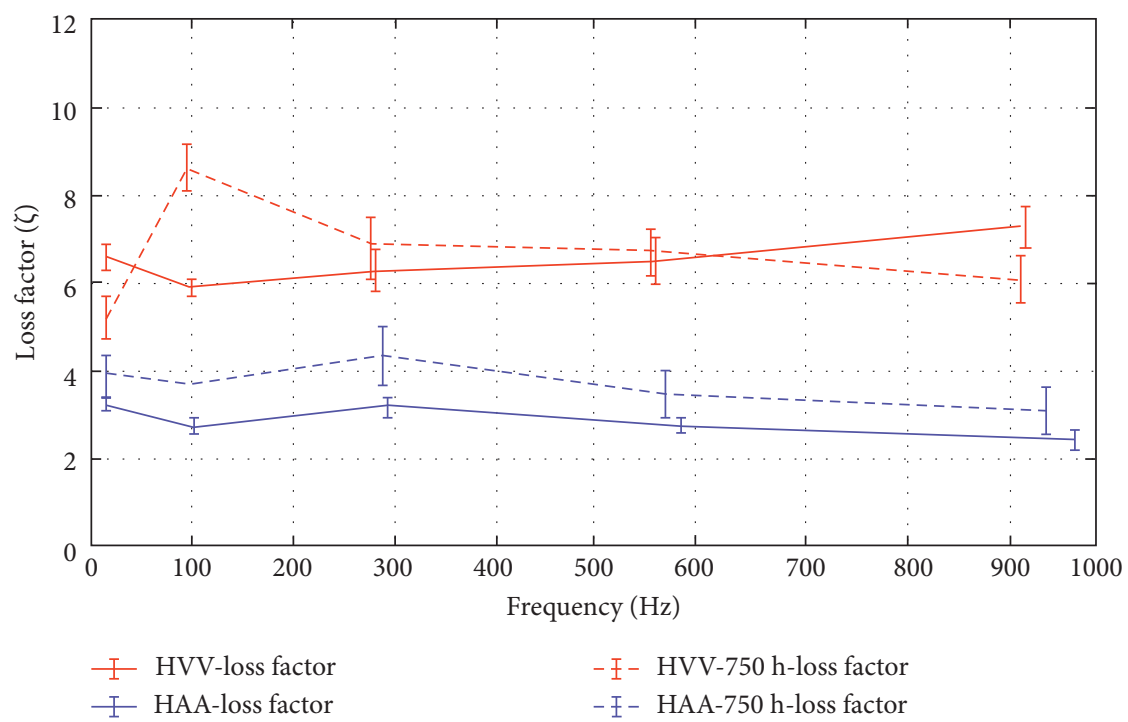

Figure 4: Plot of loss factor value with respect to frequency, recorded in a range of $0-1000 \mathrm{~Hz}$. The error bars represent the standard deviation measurement for 4 specimens according to their natural frequencies.

Young's modulus with the temperature, while the loss factor diminishes from $-20^{\circ} \mathrm{C}$ to $20^{\circ} \mathrm{C}$. High data scattering is reported at low temperatures due to the shrink effect of the damping material that twists the extremity of the specimens and moves them out from the sensor. This situation affects measurements making the test unreliable at $-20^{\circ} \mathrm{C}$.

As regards the comparison between the two elastomeric compounds, HVV loss factor is always higher than HAA before and after the climatic chamber treatment and its trend is almost constant. Moreover, this behavior is confirmed in the temperature range between $-20^{\circ} \mathrm{C}$ and $60^{\circ} \mathrm{C}$. On the other hand, HAA Young's modulus has always higher values than HVV even though it drops by $25 \%$ after $750 \mathrm{~h}$ of aging. In addition, the HAA E modulus increases with the temperature. In conclusion, experimental tests have shown that the HVV compound presents the best damping performance especially for its capability to maintain a high constant loss factor even after $750 \mathrm{~h}$ of aging cycles, so it has been chosen for the LCA application.
2.2. Virtual Correlation on Oberst Test. The virtual correlation aim on the Oberst test consists of defining the virtual material card that is able to predict the correct damping behavior of the HVV on the hybrid LCA model. In particular, to evaluate the goodness of the virtual fitting, the natural frequency values and the shape of the frequency response functions have been compared. Therefore, the experimental Oberst test has been simulated in Altair Optistruct by setting a Frequency Response Analysis (FRA). Two different specimen typologies have been modelled and correlated:

(i) Structural beam (CFRP T300 $[0]_{3}, 240 \mathrm{~g} / \mathrm{m}^{2}$ )

(ii) One-side beam (CFRP T300 $\left.[0]_{3}, 240 \mathrm{~g} / \mathrm{m}^{2}+\mathrm{HVV}\right)$

The approach used to model the carbon fiber laminate (with or without VEM) is the Equivalent Single Layer (ESL) method, where the stacking sequence is modelled on a single midsurface mesh as shown Figure 7. This modelling technique has been chosen because it will be also adopted on the 


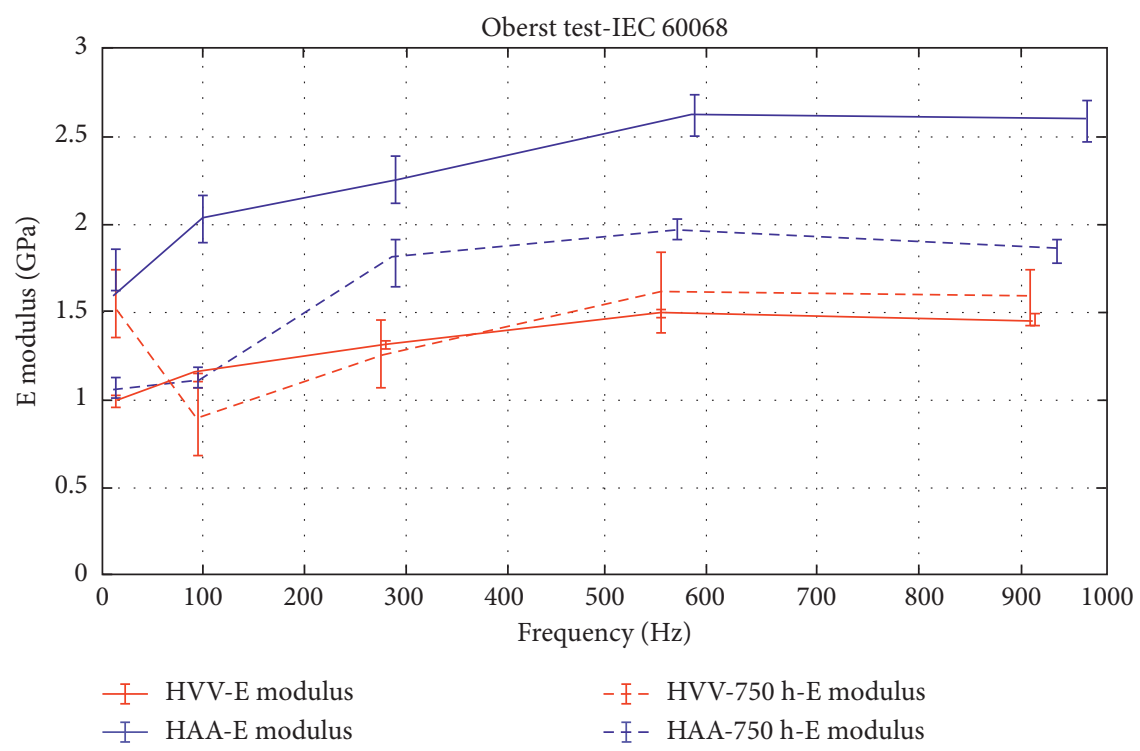

Figure 5: Plot of Young's modulus E value with respect to frequency, recorded in a range of 0-1000 Hz. The error bars represent the standard deviation measurement for 4 specimens according to their natural frequencies.

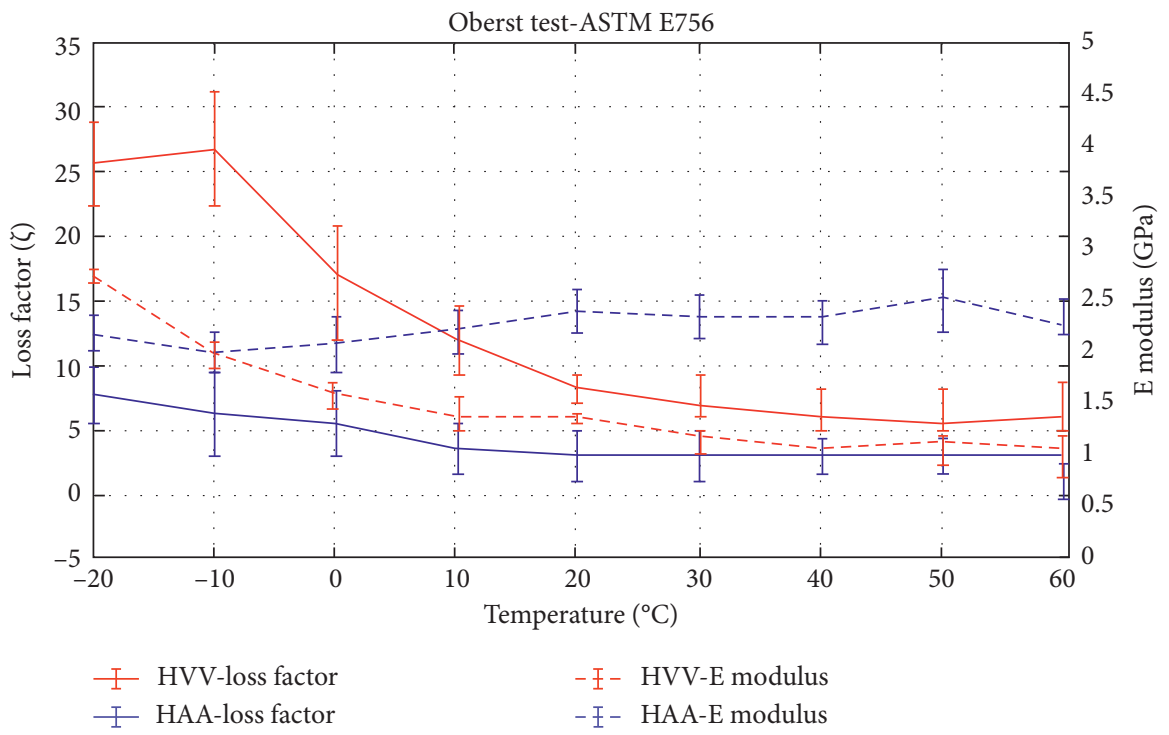

Figure 6: Plot of loss factor and Young's modulus value with respect to temperature, recorded in a range of $-20^{\circ} \mathrm{C}$ to $60^{\circ} \mathrm{C}$. The error bars represent the standard deviation measurement for 4 specimens according to each temperature step.

complete model of the hybrid lower control arm in order to reduce any possible discrepancies between samples and the LCA models.

Element properties PCOMPP, PLY, and LAMINATE define thickness, orientation, and shape of each layer and the mesh size used is equal to $4 \mathrm{~mm}$. The loss factor has been defined for every single material stacked in a laminate by using the GE USEMAT flag through a TABLED1 load collector. Because no aging or thermal effects have been considered in the virtual environment, only the untreated specimen results have been implemented and compared. The material properties of the CFRP have been defined by MAT 8 material card whose constitutive law is suitable for composite materials. The damping material has been modelled by an isotropic material card with pure elastic behavior (MATF 1 card). This assumption is based on the hypothesis that the material is subjected to small deformations and, as consequence, the simulation is performed in a linear field.

The load function applied is a sine sweep, as in the actual test, in the frequency range of $0-1100 \mathrm{~Hz}$. Therefore, to evaluate the consistency of the simulation, the computed and experimental natural frequencies with the simulation method and with the experimental one, are compared in Table 2.

The experimental values of frequency have been obtained as the average of the four tested structural beams. From the frequency comparison, the maximum observed difference is slightly over $2 \%$ on the $2^{\text {nd }}$ natural frequency, while the other 


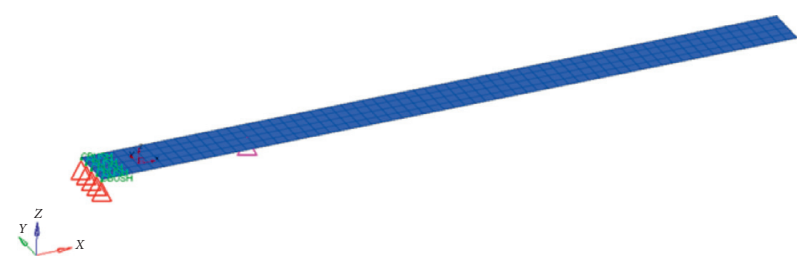

(a)

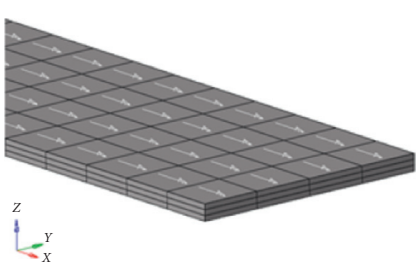

(b)

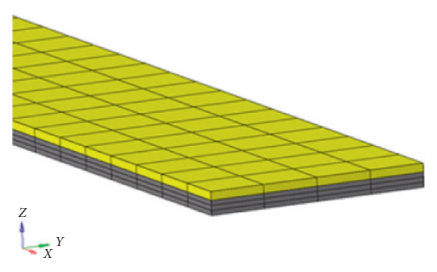

(c)

FiguRE 7: FEM Oberst specimen: (a) general setup overview, (b) structural beam specimen detail with carbon fiber orientation in white, and (c) one-side beam detail with HVV in yellow.

TABLE 2: Results comparison between experimental and FEM for the structural beam considering each mode.

\begin{tabular}{lccc}
\hline Mode & Experimental frequency $(\mathrm{Hz})$ & FEM frequency $(\mathrm{Hz})$ & Difference $(\%)$ \\
\hline 1 & 18.56 & 18.77 & +1.13 \\
2 & 114.75 & 117.47 & +2.37 \\
3 & 325.82 & 328.11 & +0.70 \\
4 & 639.27 & 640.52 & +0.19 \\
5 & 1065.3 & 1053.2 & -1.13 \\
\hline
\end{tabular}

variations are negligible. Moreover, Figure 8 reports the comparison between the computational FEM and the experimental (EXP) receptance. The trend of the FEM frequency response is very close to the experimental case; hence, the virtual model can be considered very good in correlation with the experimental data. Experimental peaks between the first two resonances are harmonics of the first natural frequency. The peak at about $300 \mathrm{~Hz}$ is due to a torsional behavior of the beam, which is not included in the FEM.

Once the structural beam has been correlated, the damped FEM models have been created. As concerns the frequency comparison, the major difference is observed in the $1^{\text {st }}$ natural frequency that is usually discarded from the evaluation, consisting in a forward shifting of $2 \%$, as reported in Table 3.

Finally, the difference between experimental and FEM results is very low and this is also confirmed by the shape of the FEM frequency response, illustrated in Figure 9, that is close to the experimental trend, especially in terms of damping.

In conclusion, FEM simulations on Oberst tests are able to catch the experimental difference between these two kinds of specimens as well as the FRFs trend. Moreover, the use of a pure elastic material card (MATF1) to model the HVV does not limit the virtual fitting procedure. In fact, since the linear simulation does not affect the accuracy of the fitting results it has been considered valid for the dynamic simulation.

Subsequently, the hybrid lower control arm has been built after a specific virtual optimization performed in Altair Optistruct and explained in [23, 24]. In particular, thanks to the specific methodology adopted, the hybrid LCA mass is $23 \%$ lower than the original one but maintains the same performance in terms of stiffness.

\section{Lower Control Arms Characterization}

3.1. Experimental Test Setup. The purpose of the test is to evaluate the dynamic performance of the two considered
LCAs and to compare their capability to damp vibrations, in particular by measuring the frequency response function in a range between 100 and $1500 \mathrm{~Hz}$. The input signal, imposed by the signal generator, is a random sequence with a flat spectrum for both the lower control arms. The exact value of the input signal on the component can be controlled and measured with a force transducer.

The response of the system is measured as the inertance between the input force and the output of 22 piezoelectric accelerometers, positioned in different points on all the surface of the component. The positioning of the accelerometers is chosen to equally distribute them in order to have results on all the surface of the components and to avoid as many modal nodes as possible. The accelerometers and force transducer configuration has been kept unmodified for both the arms to compare the global response considering the same output points. Finally, the boundary condition of the tested components has been chosen carefully to simulate a free-free condition as shown in Figure 10.

The LIPEZ method has been adopted as model parameters extraction algorithm using the Rational Fraction Polynomials (RFP) representation of the frequency response function (FRF) and, with the aim of defining a small and well-conditioned set of linear equations, and expounds a total least square method in the Z-domain [25]. Figure 11 reports the procedure scheme adopted from the experimental test to virtual data correlation. The experimental modal analysis has been carried out for a SIMO system.

The coherence function has been used as an experimental reliability index: so, every single coherence has been checked for each accelerometer for both arms after each measurement. In the end, a postprocess analysis has been done to obtain the frequency response function and compute the modal response of the system by using a properly developed MATLAB code. Finally, the modulus of every single inertance function has been summed to create a "FRF sum" to easily compare qualitatively the global 


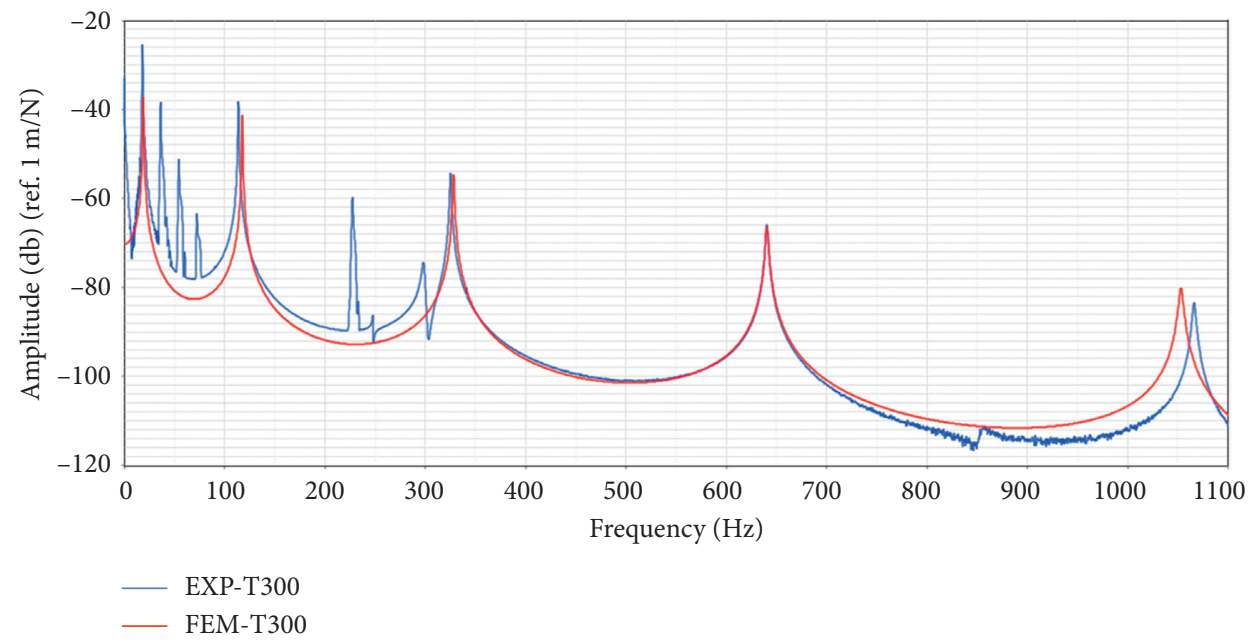

FIGURE 8: Plot of receptance (in $\mathrm{dB}$ ) with respect to frequency range: comparison between experimental (blue) and FEM (red) results for the structural beam.

TABLE 3: Results of the comparison between experimental and FEM for the one-side beam considering each mode.

\begin{tabular}{lccc}
\hline Mode & Experimental frequency $(\mathrm{Hz})$ & FEM frequency $(\mathrm{Hz})$ & Difference $(\%)$ \\
\hline 1 & 15.98 & 16.36 & +2.37 \\
2 & 99.23 & 101.36 & +2.14 \\
3 & 283.32 & 285.79 & +0.87 \\
4 & 560.64 & 557.51 & -0.55 \\
5 & 930.78 & 915.68 & -1.62 \\
\hline
\end{tabular}

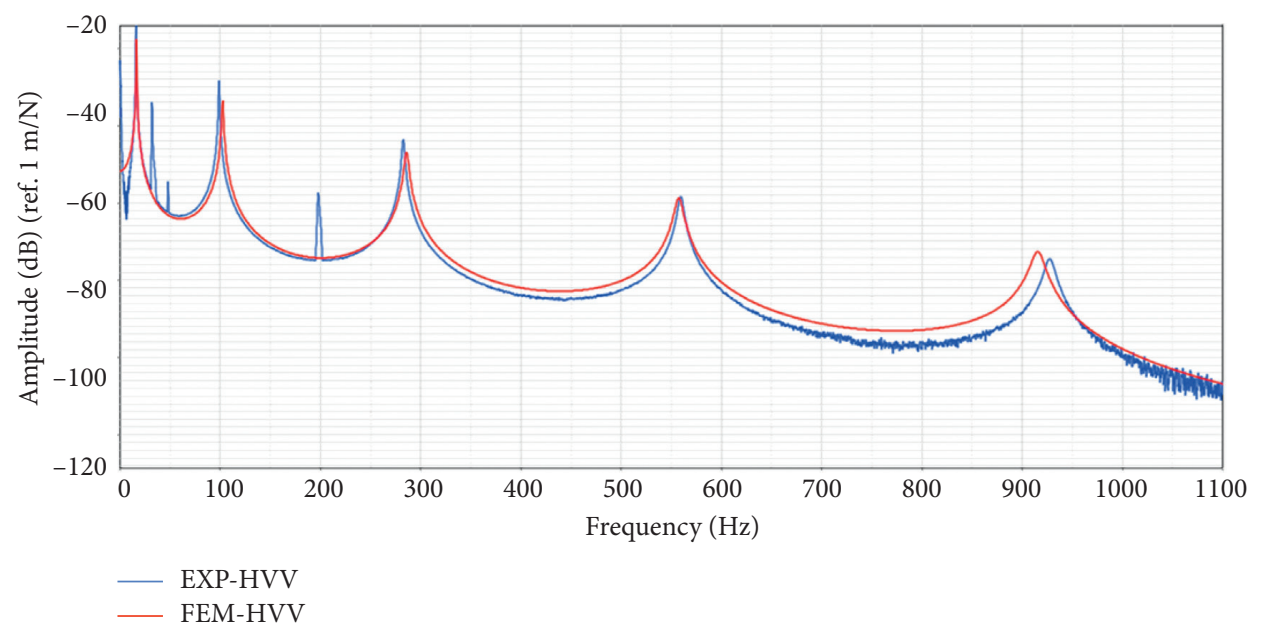

FIGURE 9: Plot of receptance (in $\mathrm{dB}$ ) with respect to frequency range: comparison between experimental (blue) and FEM (red) results for the one-side beam.

results between FEM and experimental tests. In this way, the evaluation of the modal parameters such as the damping effect becomes more direct and intuitive.

3.2. Baseline Experimental Modal Analysis. Figure 12 presents the stabilization diagram of the baseline LCA with the number of extracted poles for each identified mode. Very stable frequency lines even at low orders are present, especially for the two peaks at about $400 \mathrm{~Hz}$ and $650 \mathrm{~Hz}$.
Then, modes are considered stable when, for a given frequency, damping is stable for each extracted eigenvalue as shown in Figure 13.

Three computational modes are present at about 190, 300 , and $370 \mathrm{~Hz}$ : their frequencies do not correspond to evident peaks in the response and their damping values are very scattered and unstable. On the contrary, modes 5 and 6 at about 780 and $850 \mathrm{~Hz}$ have been considered stable. This phenomenon was caused by the low excitation of the system due to the input load position that was close to a node of these mode shapes. 


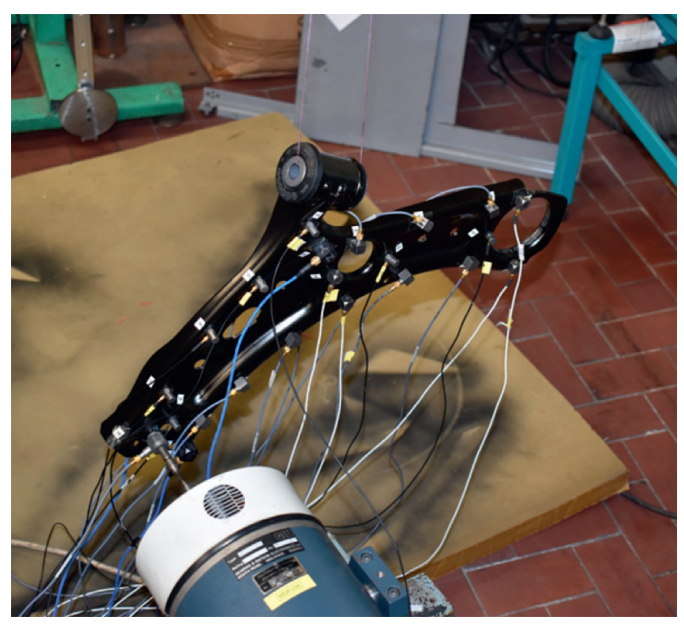

(a)

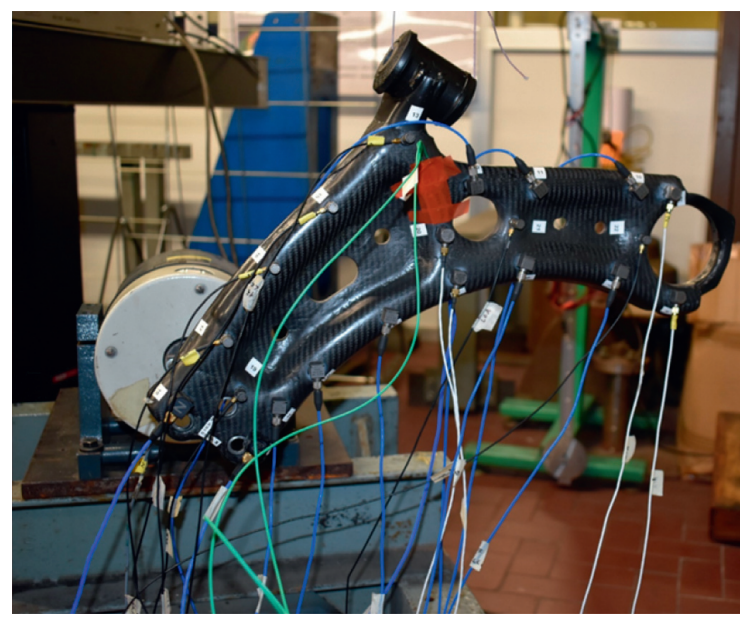

(b)

Figure 10: (a) Baseline. (b) Hybrid. LCA prepared for the experimental modal analysis with accelerometers and shaker positioned.

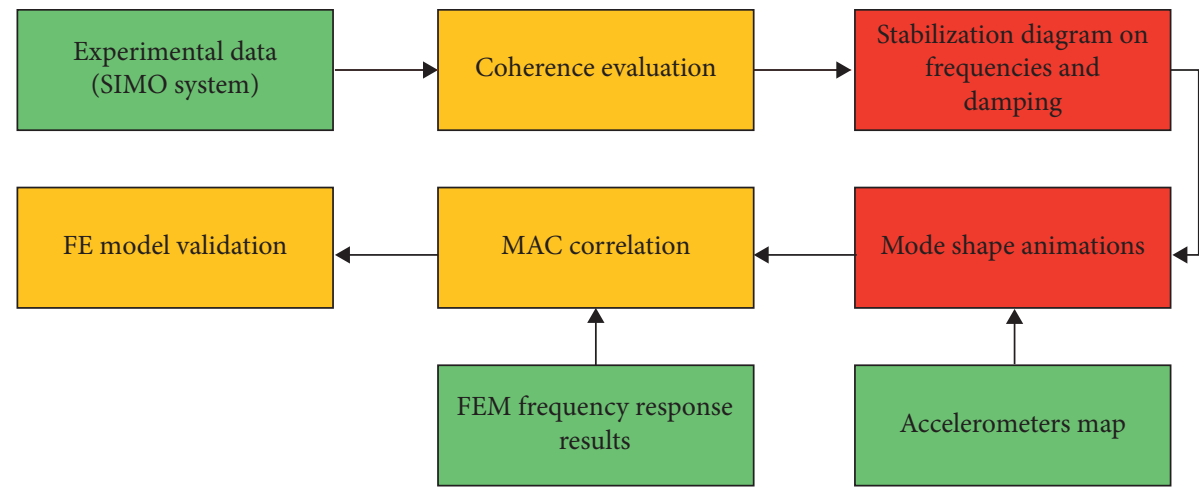

FIgURE 11: Methodology path adopted to carry out results from modal experimental tests and to correlate them with the FEM.

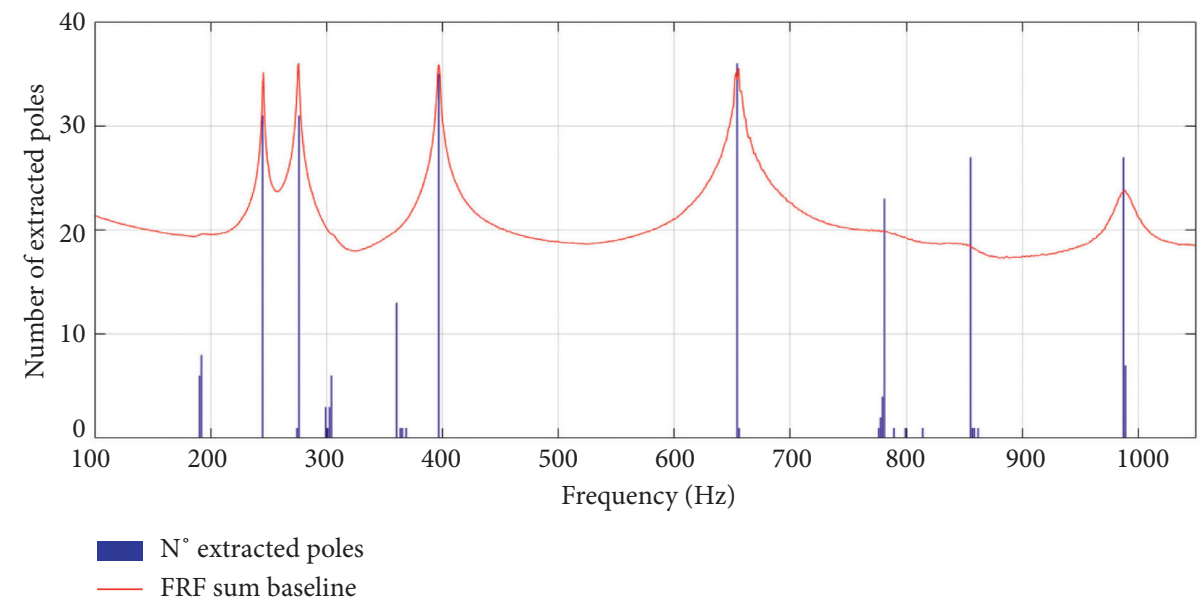

FIgURE 12: The number of extracted poles with respect to frequency for the baseline LCA. Each line corresponds to the number of occurrences of an estimated frequency in the selected band. In red is reported the FRF sum.

3.3. Hybrid Experimental Modal Analysis. Figure 14 presents the stabilization diagram of the hybrid LCA with the number of extracted poles for each identified mode. Three main peaks from $250 \mathrm{~Hz}$ to $700 \mathrm{~Hz}$ are very stable from low orders; in particular the $2^{\text {nd }}$ and the $4^{\text {th }}$ are those with a high energetic contribution. 


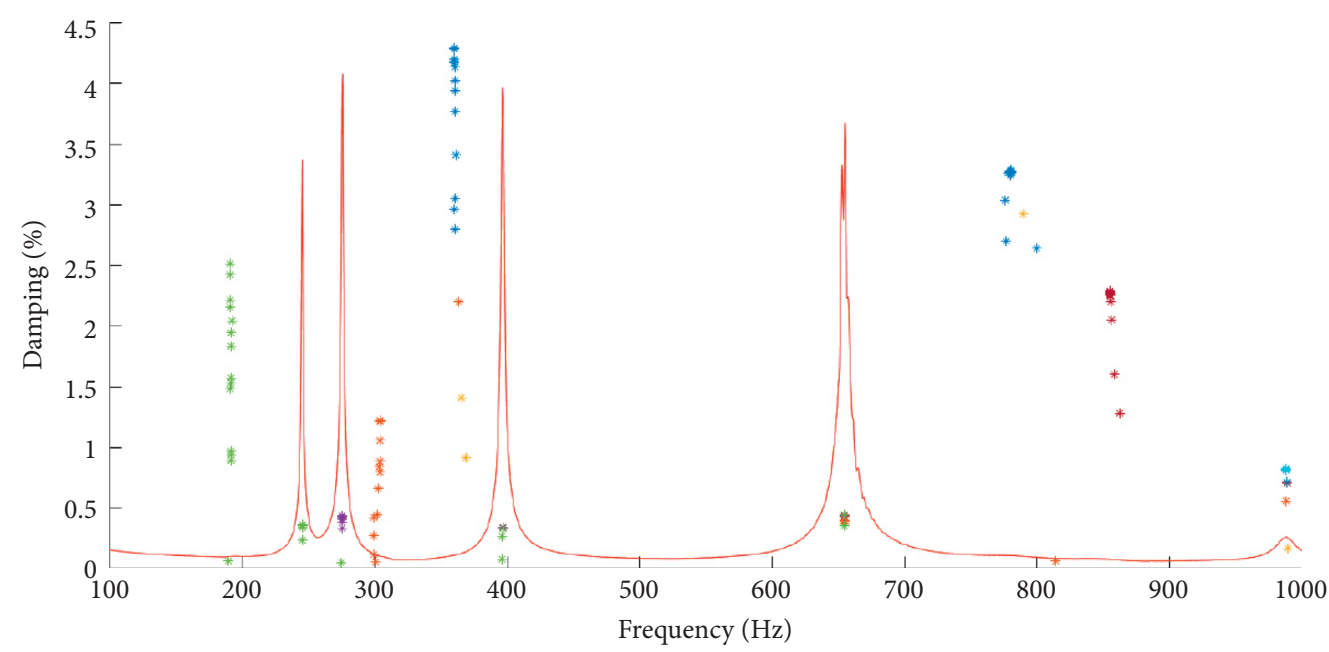

FIGURE 13: Plot of damping ratio (in percentage) with respect to frequency for the baseline LCA. Each “*” corresponds to the pair natural frequency/damping ratio, given the model order $\mathrm{n}$ (ranging from 3 to 40). The FRFs sum (in red) is plotted in the background.

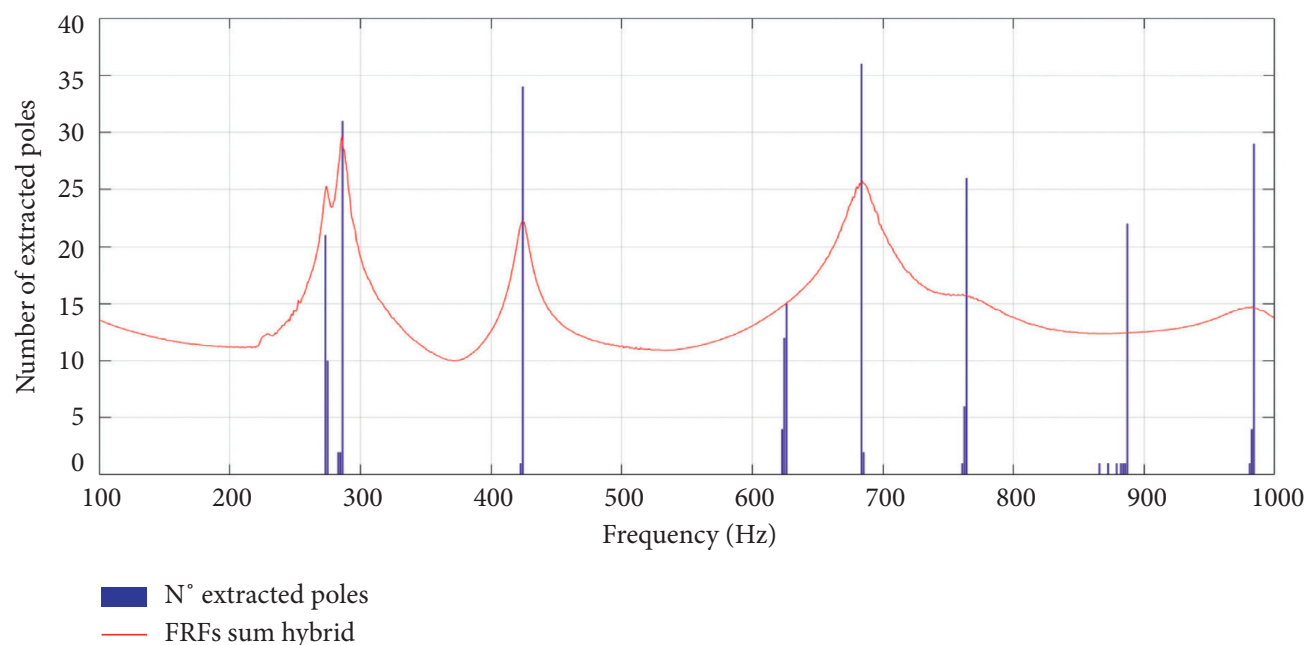

Figure 14: Plot of the number of extracted poles with respect to the frequency range for the hybrid LCA. Each line corresponds to an estimated frequency in the selected band, given the model order $\mathrm{n}$ (ranging from 3 to 40).

For the hybrid LCA, two computational modes have been found: one around $630 \mathrm{~Hz}$ and the other around $900 \mathrm{~Hz}$. Although their frequency stabilization diagram is quite stable, these two modes have been discarded because their shapes are not plausible and the damping is unrealistically high, as shown in Figure 15. Therefore, for the hybrid LCA, the total number of structural modes extracted is six in the range of $100-1000 \mathrm{~Hz}$.

Comparing the experimental results, the hybrid lower control arm shows a sensible improvement in terms of damping performance. In particular, the hybrid LCA damping ratio increases at least 3,5 times for each eigenmode as shown in Table 4, with the exception of modes 5 and 6 where the damping ratio is only slightly higher than the baseline.

The reduced number of modes for the hybrid LCA may have been caused by the presence of HVV material which could have moved the higher modes in an upper-frequency band. In fact, in Figure 16, the comparison of the FRF sum of the hybrid and baseline arms is plotted and the effect of damping material can be easily appreciated. By comparing the dynamic response between the baseline LCA (in blue) and the hybrid (in red) an efficient vibration reduction is clearly depicted since the first modes in smooth of the peaks are strongly evident. In addition, the combined effect of mass and stiffness variation determined a frequency shifting of maximum $10 \%$ for the $1^{\text {st }}$ mode, whereas for the others it is less than $6 \%$. This aspect implies that the original range of natural frequency tuned by the OEM (Original Equipment Manufacturer) for the baseline LCA has been kept also in the hybrid arm, although materials and mass are totally changed.

3.4. Virtual-Experimental Correlation on LCA. The experimental modal analysis has been reproduced in Optistruct by setting a frequency response simulation, as in the case of the Oberst test correlation. The FEM models are defined 


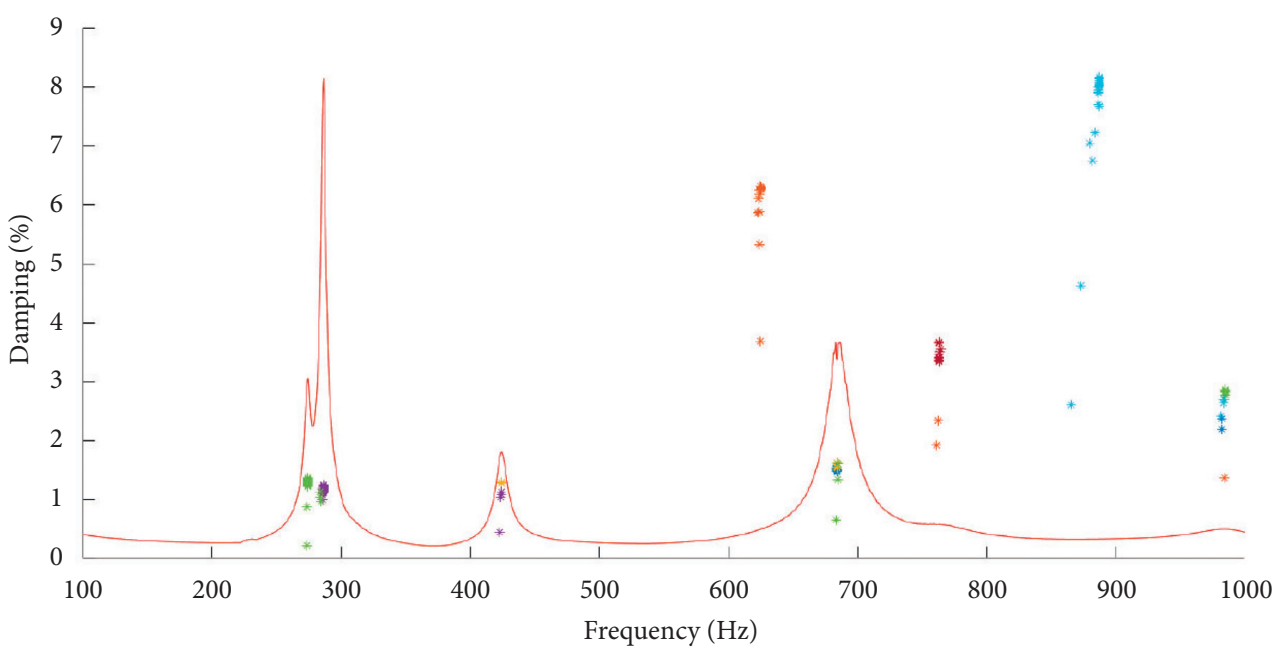

FIGURE 15: Plot of damping ratio (in percentage) with respect to the frequency range for the hybrid LCA. Each “*” corresponds to the pair natural frequency damping ratio, given the model order $n$ (ranging from 3 to 40). The FRFs sum (in red) is plotted in the background.

TABLE 4: Experimental results of baseline and hybrid LCA: the comparison takes into account the frequency and the damping ratio for each extracted mode.

\begin{tabular}{lcccc}
\hline Eigenmode & Baseline exp. frequency $(\mathrm{Hz})$ & Hybrid exp. frequency $(\mathrm{Hz})$ & Damping ratio baseline (\%) & Damping ratio hybrid (\%) \\
\hline 1 & 245.43 & 274.14 & 0.36 & 1.28 \\
2 & 275.69 & 286.18 & 0.42 & 1.23 \\
3 & 396.78 & 424.21 & 0.33 & 1.29 \\
4 & 654.62 & 683.48 & 0.4 & 1.5 \\
5 & 780.18 & 763.26 & 3.25 & 3.39 \\
6 & 855.55 & 984.45 & 2.25 & -76 \\
7 & 988.09 & - & 0.82 & - \\
\hline
\end{tabular}

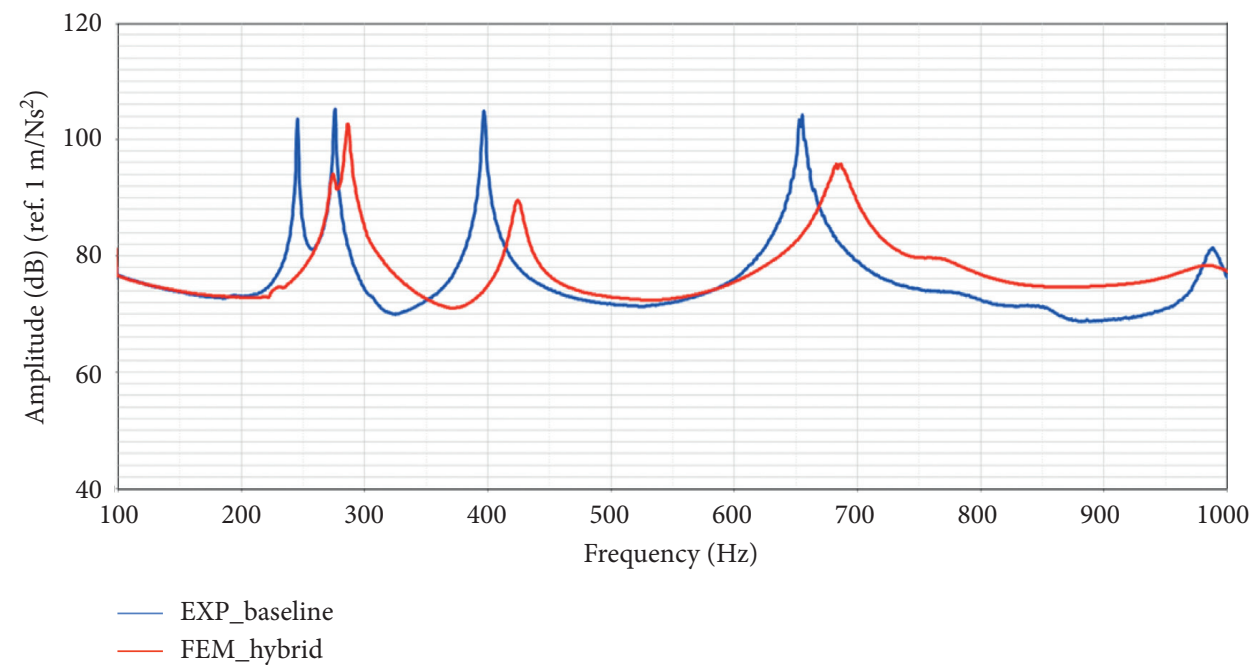

FIGURE 16: FRFs comparison between baseline (blue) and hybrid (red) arm: the plot represents the sum of every single inertance amplitude in $\mathrm{dB}$ in the frequency range of interest.

to replicate as much as possible the real components in order to predict their dynamic behavior. Modal analysis simulation is very sensitive to model details: for instance, mass distribution is fundamental to get a well correlated FRF as also geometry definition and local stiffness. The LCA has been created in the virtual environment through a $3 \mathrm{D}$ scanning of the original component. Thus, its surfaces have been built through a CAD software and then meshed inside Altair Hypermesh. Subsequently, the accelerometer map has been reproduced on the model according to the experimental positions as shown in Figure 17. The concentrated mass elements (CONM2) has been used to model the accelerometer mass on each specific node. 


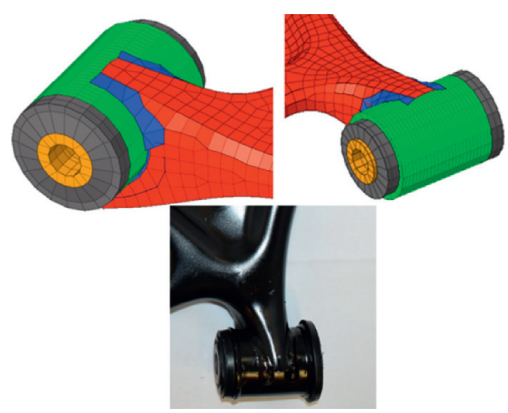

(a)

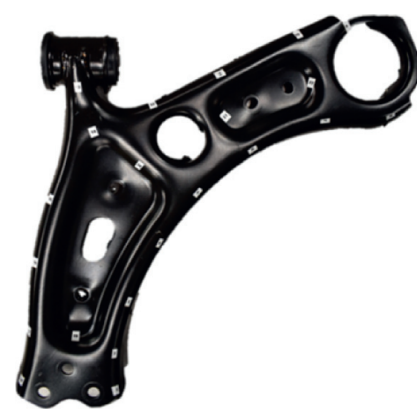

(b)

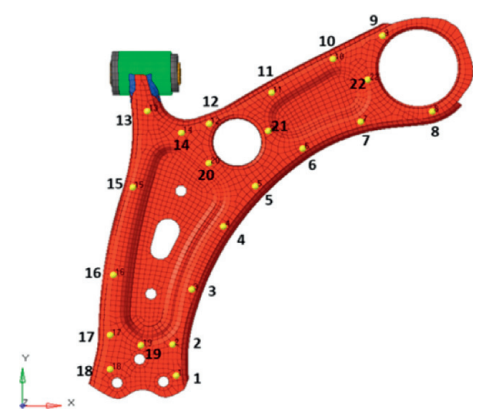

(c)

FIGURE 17: LCA FEM model: (a) detail comparison on the front bushing, (b) accelerometer position markers applied on the real arm and (c) reproduced on the FEM one.

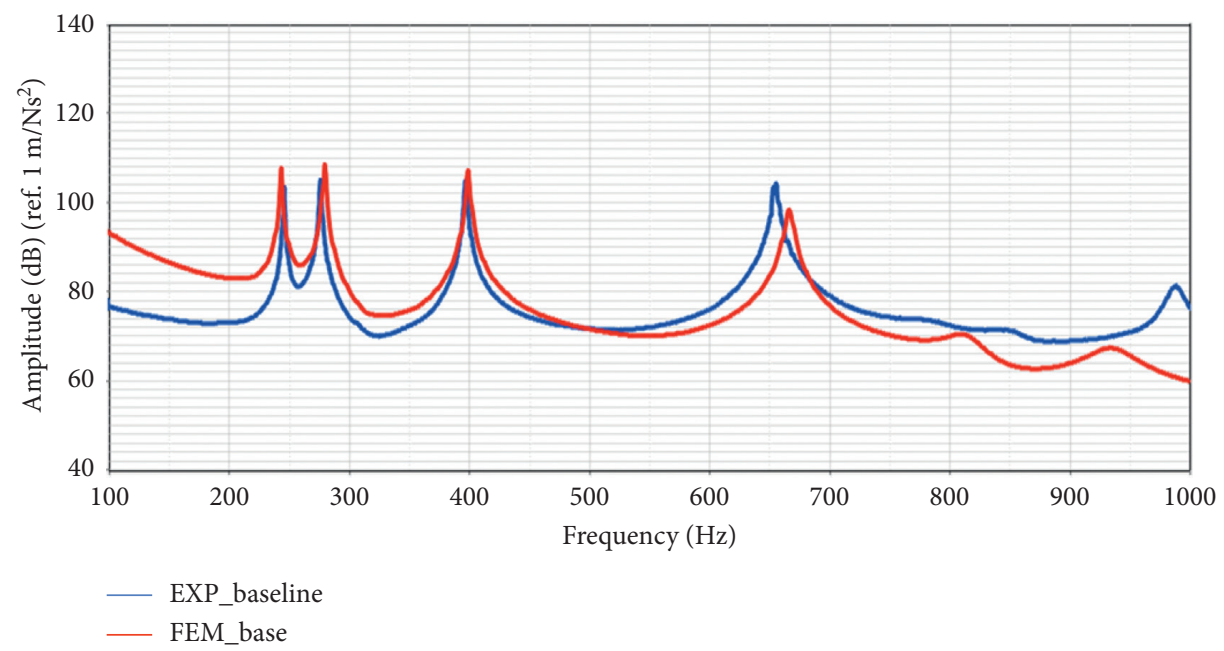

FIGURE 18: FRFs comparison between experimental (blue) and FEM (red) baseline arm: the plot represents the inertance amplitude in dB in the frequency range of interest.

The FEM exploits the same material cards tuned for the Oberst model, in which the experimental data were already implemented. The correlation between the virtual model and the experimental test has been conducted evaluating the frequency shifting, the trend of the FRF, and the MAC (Modal Assurance Criterion) coefficient.

For the baseline frequency response function, an excellent correlation in terms of frequency values is observed until $650 \mathrm{~Hz}$ as shown in, where the experimental inertance is reported in blue while the FEM in red (Figure 18). Virtual FRF is perfectly correlated with the experimental behavior with errors on frequency estimation less than 2\%. After $700 \mathrm{~Hz}$, FEM model starts to lose accuracy: errors become higher with a maximum difference of $9 \%$ on the six mode. Nevertheless, FEM solver is not able to find out the mode shape between $800 \mathrm{~Hz}$ and $900 \mathrm{~Hz}$. This phenomenon may be related to the accuracy level of the CAD or FEM model. In fact, at low frequency $(200-600 \mathrm{~Hz})$, modes involve the global behavior of the structure while, at higher frequencies (700-1000 Hz), modes are mainly influenced by local stiffness or geometry variation. Therefore, small modification adopted in terms of mesh discretization or geometry simplification may have affected the virtual frequency response function.

This situation is also confirmed by MAC index, in Figure 19, which is close to 1 for the first four mode shapes while a sensible worsening is highlighted for modes 5 and 6. In particular, virtual mode shape 6 is not comparable with experimental mode shape 6 and according to the MAC matrix could be more similar to experimental mode shape 5 .

For instance, the first three virtual mode shapes have been reported in Figure 20.

Table 5 summarizes the complete comparison between FEM and the experimental test for the baseline arm.

As concerns the hybrid virtual modal analysis, the trend of the FRF shows a good correlation in terms of frequencies as can be observed in Figure 21, where the experimental inertance is reported in blue while the FEM in red. In this case, the virtual model is not able to match the first two modes trend although the damping behavior is nicely correlated. In this specific case, the correlation is more sensitive to each single variation due to the lamination process of the hybrid LCA. In fact, some aspects are really difficult to reproduce on the FEM model: two clear 


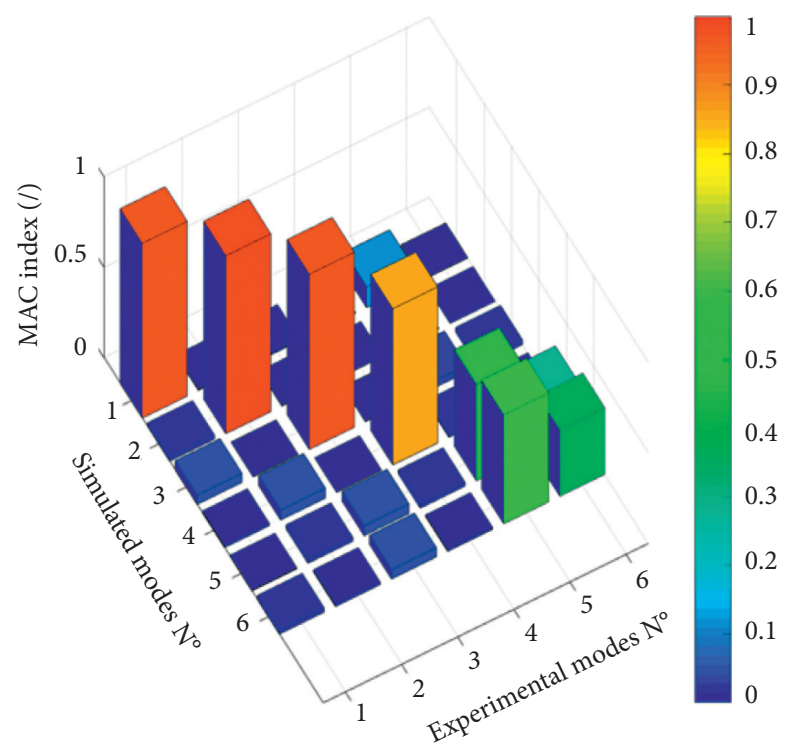

Figure 19: Baseline arm MAC: the index compares the simulated and the experimental mode shapes.

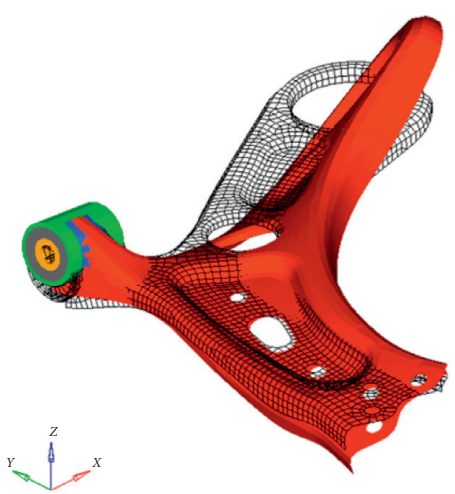

(a)

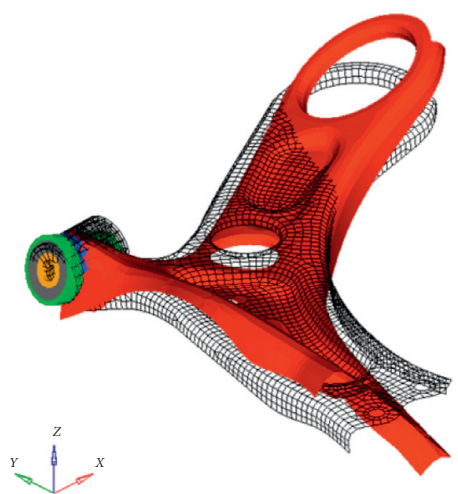

(b)

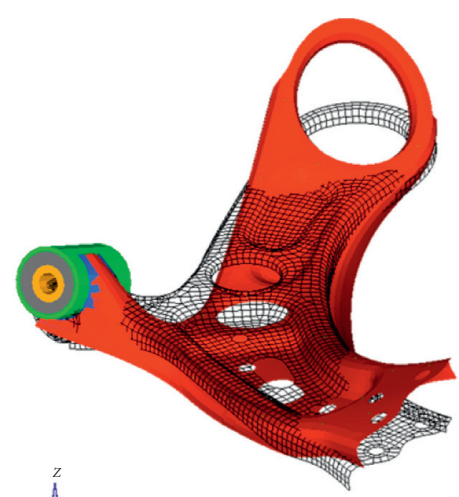

(c)

Figure 20: First three FEM mode shapes for the baseline arm: the undeformed shape is represented in black. (a) Mode shape $f_{1}=243 \mathrm{~Hz}$. (b) Mode shape $f_{2}=279 \mathrm{~Hz}$. (c) Mode shape $f_{3}=398 \mathrm{~Hz}$.

TABLE 5: Correlation results of experimental and FEM baseline LCA: the comparison takes into account the frequency and the MAC for each mode.

\begin{tabular}{lcccc}
\hline Eigenmode baseline & Frequency FEM $(\mathrm{Hz})$ & Frequency EXP $(\mathrm{Hz})$ & $\Delta$ frequency $(\%)$ & -0.99 \\
\\
1 & 243 & 245.43 & +1.20 & Diag $(\mathrm{MAC})$ \\
2 & 279 & 275.69 & +0.31 & 0.965 \\
3 & 398 & 396.78 & +1.74 & 0.982 \\
4 & 666 & 654.62 & +4.08 & 0.967 \\
5 & 812 & 780.18 & +9.05 & 0.863 \\
6 & 933 & 855.55 & - & 0.366 \\
7 & - & 988.09 & - \\
\hline
\end{tabular}

examples are the impossibility of controlling the thickness variation along the arm or the exact fiber orientation of the plies. Despite this, the difference between the frequencies is less than $5 \%$ except for the first mode, which is about $7 \%$.
However, MAC index in Figure 22 confirms the correctness of the overall correlation because it is close to 1 for the first four mode shapes as in the case of the baseline arm. The situation is worse for mode shapes 5 and 6 that are not comparable with the experimental ones. 


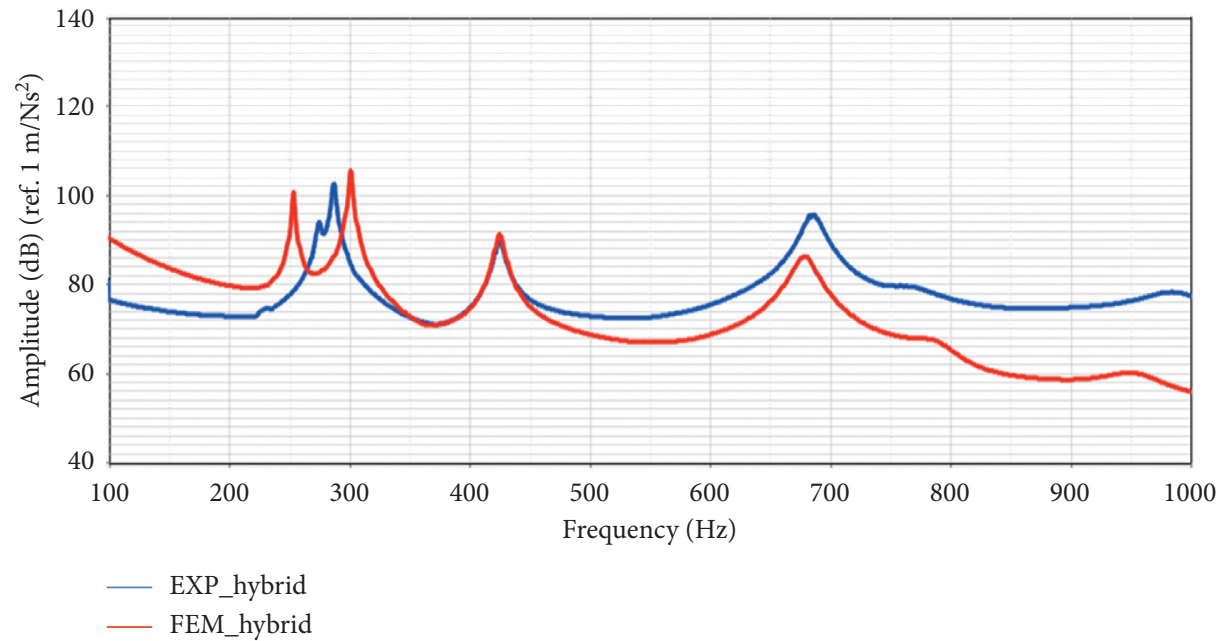

FIGURE 21: FRFs comparison between experimental (blue) and FEM (red) hybrid arm: the plot represents the inertance amplitude in dB in the frequency range of interest.

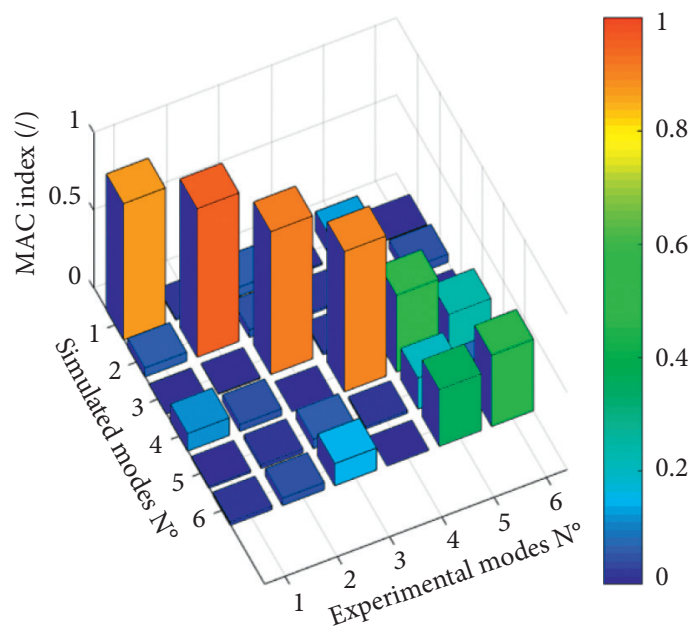

Figure 22: Hybrid arm MAC: the index compares the simulated and the experimental mode shapes.

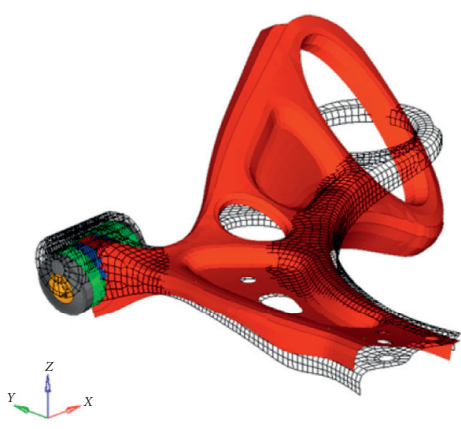

(a)

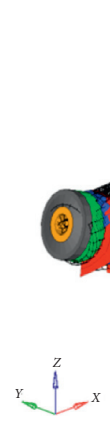

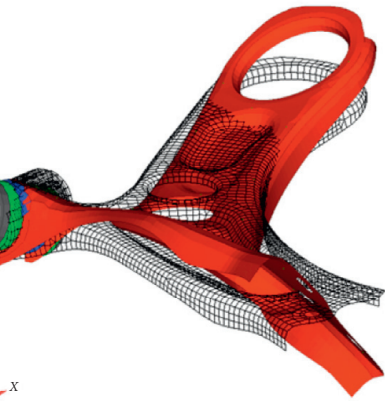

(b)

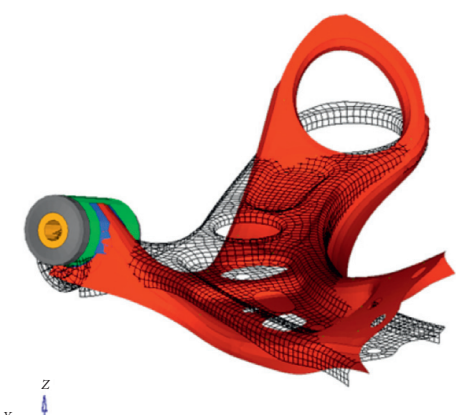

(c)

FiguRE 23: The first three FEM mode shapes for the Hybrid arm: the undeformed shape is represented in black. (a) Mode shape $\mathrm{f}_{1}=253 \mathrm{~Hz}$. (b) Mode shape $f_{2}=300 \mathrm{~Hz}$. (c) Mode shape $f_{3}=424 \mathrm{~Hz}$. 
TABLE 6: Correlation results of experimental and FEM hybrid LCA the comparison takes into account the frequency and the MAC for each mode.

\begin{tabular}{|c|c|c|c|c|}
\hline Eigenmode hybrid & Frequency FEM (Hz) & Frequency EXP $(\mathrm{Hz})$ & $\Delta$ frequency $(\%)$ & Diag (MAC) \\
\hline 1 & 253 & 274.14 & -7.71 & 0.873 \\
\hline 2 & 300 & 286.18 & 4.83 & 0.952 \\
\hline 3 & 424 & 424.21 & -0.05 & 0.916 \\
\hline 4 & 678 & 683.48 & -0.80 & 0.899 \\
\hline 5 & 787 & 763.26 & 3.11 & 0.199 \\
\hline 6 & 952 & 984.45 & -3.30 & 0.457 \\
\hline
\end{tabular}

For instance, the first three virtual mode shapes have been reported in Figure 23.

Table 6 summarizes the comparison between FEM and experimental test for the hybrid arm.

In conclusion, the experimental tests highlight the excellent damping vibration properties of the hybrid lower control arm that are for the first four modes 3,5 times higher than the baseline component. Although FEM models are very sensible to geometric or stiffness variation on the real component, a very good correlation has been obtained between virtual and experimental tests. For this reason, the design procedure from Oberst test materials characterization to the modal analysis of actual components is considered valid.

\section{Conclusions}

The main goal of this paper is the description of the design procedure to enhance the damping properties of a multimaterial lightweight suspension arm of a McPherson suspension for a C-segment vehicle. An innovative viscoelastic material has been used to join carbon fiber with steel that works as a passive constrained layer damper and adhesive simultaneously. Therefore, the hybrid technology applied has been focused to reduce the LCA mass, diminishing the steel thickness and adding a CFRP tailored cover without compromising the global mechanical performance. Particular attention has been paid to the investigation of the dynamic response in terms of vibration reduction especially in the range of structure-borne frequencies of $0-600 \mathrm{~Hz}$.

Two viscoelastic materials have been compared in order to evaluate their damping properties. These two compounds have been tested in a wide frequency and temperature range (ASTM E756-05 and SAE J1637) and after an aging treatment of $750 \mathrm{~h}$ (IEC 60068) in order to define their Young's moduli and loss factors at different conditions.

Experimental tests have shown that the HVV compound presents the best damping performance especially for its capability to maintain a high constant loss factor even after $750 \mathrm{~h}$ of aging.

Dynamic tests in Altair Optistruct have been performed to virtually reproduce the ASTM 756-05 test, to correlate virtual and real tests.

The results obtained from the Oberst test have allowed defining a specific Optistruct card material able to virtually reproduce the damping effect of the HVV even in the LCA complete model.
Modal analysis tests have been conducted on both the arms to compare their experimental performance in terms of damping and frequency and to validate the methodological design approach by FEM correlation. LIPEZ modal extraction parameters method has been successfully applied to find out the inertance, mode shapes, and damping ratios of the two lower control arms. Hybrid LCA demonstrated excellent damping capabilities due to the application of HVV compound, increasing 3,5 times the damping ratio for the first four modes between 100 and $600 \mathrm{~Hz}$. Moreover, the frequency shift between baseline and hybrid is limited to a maximum of $10 \%$ for only the first mode whereas for the others it is less than $6 \%$. Therefore, the hybrid arm is tuned in the same range of natural frequencies defined by the OEM for the baseline LCA.

High correlation levels have been obtained between the experimental modal analysis and the virtual frequency response. FEM models are able to reproduce a very good correlated FRF in terms of frequency and damping, with a high MAC correspondence especially for the first four modes, whose values are over 0,85. Nevertheless, FEM modal analysis is strongly sensible to the geometry fidelity to the real component. The accuracy of the CAD and FEM models is crucial for the correlation on eigenmodes and eigenfrequencies. In fact, it has been found out that the correlation at higher frequencies $(700-1000 \mathrm{~Hz})$ is poor because modes are mainly influenced by local stiffness or geometry variation. Therefore, small modification adopted in terms of mesh discretization or geometry simplification may have affected the virtual frequency response function. This effect is more evident in the case of hybrid LCA where the last modes have the MAC index below 0,5. Finally, the proposed hybrid design integrates an innovative solution to face problems of mechanical coupling between dissimilar materials for a complex component such as a swinging arm, achieving at the same time vibration reduction. In fact, the hybrid LCA global damping is more than tripled with respect to the baseline LCA, due to the excellent damping capabilities of the HVV material. Moreover, FEM simulations are a key enabling technology especially for composite design, but high model accuracy is needed to obtain reliable and predictive models for both structural and dynamic analysis.

\section{Data Availability}

Access to data is restricted due to commercial confidentiality. 


\section{Conflicts of Interest}

The authors declare that there are no conflicts of interest.

\section{Acknowledgments}

The authors want to thank, for the helpful and continuous support, Altair Engineering Srl for FEM software, 3VU and SFC Compositi for the LCA manufacturing, BeonD Srl for the technical and engineering advice, and KRAIBURG for suppling VEMs samples. The research has been made using the own funds of the Research Group IEHV (Innovative Electric and Hybrid Vehicles).

\section{References}

[1] Climate Action-European Commission, Proposal for Post$2020 \mathrm{CO}_{2}$ Targets for Cars and Vans, Climate Action-European Commission, Brussels, Belgium, 2017.

[2] N. Lutsey and P. Nicholas, Review of technical literature and trends related to automobile mass-reduction technology, Institute of Transportation Studies, UC Davis, Institute of Transportation Studies, Davis, CA, USA, 2010.

[3] M. Carello, A. G. Airale, A. Ferraris, A. Messana, and L. Sisca, "Static design and finite element analysis of innovative CFRP transverse leaf spring," Applied Composite Materials, vol. 24, no. 6, pp. 1493-1508, 2017.

[4] S. Xu, A. Ferraris, A. G. Airale, and M. Carello, "Elasto-kinematics design of an innovative composite material suspension system," Mechanical Sciences, vol. 8, no. 1, pp. 11-22, 2017.

[5] M. Carello and A. G. Airale, "Composite suspension arm optimization for the city vehicle XAM 2.0," in Advanced Structural Material Design and Computation of Modern Engineering Materials, pp. 257-272, Springer, Berlin, Germany, 2014.

[6] M. Carello, A. G. Airale, and A. Ferraris, "City vehicle XAM 2.0: design and optimization of the composite suspension system," SAE Technical Paper Series, vol. 1, 2014.

[7] R. Salloum, P. Töws, S. Schmidt, D. Mayer, D. Spancken, and A. Büter, "Vibration damping of a composite control arm through embedded piezoceramic patches shunted with a negative capacitance," in Smarte Strukturen Und Systeme, pp. 182-193, De Gruyter Oldenbourg, Munich, Germany, 2016.

[8] M. A. Panza, "A review of experimental techniques for $\mathrm{NVH}$ analysis on a commercial vehicle," Energy Procedia, vol. 82, pp. 1017-1023, 2015.

[9] R. Salloum, O. Heuss, and D. Mayer, "Global optimization of smart lightweight structures," in Proceedings of International Conference on Noise and Vibration Engineering, ISMA 2014, Leuven, Belgium, September 2014.

[10] R. Salloum, Optimization of shunt damped composite structures using negative capacitances, $\mathrm{PhD}$ Thesis, Technische Universität Darmstadt, Darmstadt, Germany, 2016.

[11] R. Salloum, O. Heuss, and D. Mayer, "Design of smart lightweight structures: simultaneous optimization of mechanical and shunt circuit parameters," in Proceedings of the ICAST 2014-25th International Conference on Adaptive Structures and Technologies, The Hague, The Netherlands, October 2014.

[12] A. Fasana, A. Ferraris, D. B. Polato, A. G. Airale, and M. Carello, "Composite and damping materials characterization with an application to a car door," in Advances in Italian Mechanism Science, pp. 174-184, Springer, Berlin, Germany, 2019.

[13] A. Fasana, A. Ferraris, A. G. Airale, D. Berti Polato, and M. Carello, "Experimental characterization of damped CFRP materials with an application to a lightweight car door," Shock and Vibration, vol. 2017, Article ID 7129058, 9 pages, 2017.

[14] A. Fasana, A. Ferraris, A. G. Airale, D. B. Polato, and M. Carello, "Oberst and aging tests of damped cfrp materials: new fitting procedure and experimental results," Composites Part B: Engineering, vol. 148, pp. 104-113, 2018.

[15] W. Liebig, V. Sessner, K. A. Weidenmann, and L. Kärgeret, "Numerical and experimental investigations of the damping behaviour of hybrid cfrp-elastomer-metal laminates," Composite Structures, vol. 202, pp. 1109-1113, 2018.

[16] M. M. Stoll and K. A. Weidenmann, "Materials selection for a fiber-metal-laminate with elastomer interlayers," in Proceedings of the 21st International Conference on Composite Materials ICCM 2017, Xi'an, China, August 2017.

[17] J. Krollmann, T. Schreyer, M. Veidt, and K. Drechsler, "Impact and post-impact properties of hybrid-matrix laminates based on carbon fiber-reinforced epoxy and elastomer subjected to low-velocity impacts," Composite Structures, vol. 208, pp. 535-545, 2019.

[18] M. Stoll, F. Stemmer, S. Ilinzeer, and K. A. Weidenmann, "Optimization of corrosive properties of carbon fiber reinforced aluminum laminates due to integration of an elastomer interlayer," Key Engineering Materials, vol. 742, pp. 287-293, 2017.

[19] N. A. Jayasree, A. G. Airale, A. Ferraris, A. Messana, L. Sisca, and M. Carello, "Process analysis for structural optimisation of thermoplastic composite component using the building block approach," Composite Part B: Engineering, vol. 126, pp. 119-132, 2017.

[20] ASTM, Standard Test Method for Measuring VibrationDamping Properties of Materials, ASTM International, West Conshohocken, PA, USA, 2017.

[21] SAE International, Laboratory Measurement of the Composite Vibration Damping Properties of Materials on a Supporting Steel Bar, SAE International, Warrendale, PA, USA, 2013.

[22] IEC webstore Environmental testing-part 2-78: tests-test cab: damp heat, steady state. IEC webstore, 2012.

[23] A. Messana, Suspension lower control arm case study: enhancing lightweight and vibration reduction, $\mathrm{PhD}$ Thesis, Polytechnico di Torino, Turin, Italy, 2019.

[24] A. Messana, L. Sisca, A. Ferraris et al., "Lightweight design of a multi-material suspension lower control arm," in Proceedings of the ASME 2020 International Design Engineering Technical Conferences and Computers and Information in Engineering Conference, St Louis, MO, USA, August 2020.

[25] A. Fasana, "Modal parameters estimation in the Z-domain," Mechanical Systems and Signal Processing, vol. 23, no. 1, pp. 217-225, 2009. 